\title{
INSULIN ABSORPTION BY THE CONJUNCTIVAL MEMBRANES IN RABBITS
}

By C. D. CHRISTIE AND R. F. HANZAL

(From the Department of Medicine and the Institute of Pathology, Western Reserve University, Cleveland)

(Received for publication July 7, 1931)

The disadvantages of repeated subcutaneous insulin injections in the treatment of diabetes mellitus are well known. Numerous attempts have been made to find a more satisfactory route, which have largely centered around absorption from mucous surfaces. Generally the results have been uncertain, uneconomical, and at times impracticable, in spite of alterations in insulin and its use in combinations with other substances. There are many excellent reviews in the literature covering this subject, and one especially complete by Stammers (1).

There is no reference in the literature concerning absorption of insulin from the conjunctival membranes. Success by this route would obviate certain of the major objections to the hypodermic method. The animal experiments herewith reported have been carried out to determine the practicability as to rate, duration and constancy of absorption of insulin usage by the instillation of it in the conjunctival sac. Such instillation cannot be made in animals without waste, which should not occur in man, so it is therefore impossible to give accurate quantitative expression to the relative effectiveness of insulin by this route as compared to the subcutaneous injections. It is felt that more accurate data as to the economic possibilities of this method can best be determined by actual studies on human diabetics. We are now engaged in such studies. For our work in the clinic we have started with dry insulin, dissolving it in a menstrum, which both lessens the high $\mathrm{pH}$ of commercial insulin and frees it from phenol, which we believe makes it absolutely safe for conjunctival instillation. In addition we have developed a dropping device which eliminates the danger of trauma to the eye and measures the dose with fair accuracy. 


\section{METHOD OF STUDY}

Rabbits which weighed as near two kilograms as possible were selected for this work. Blood was obtained from the ear veins and sugar determinations made by the micro method of Folin. The rabbits were fasted from 12 to 24 hours, and the fasting sugar level determined just before each insulin instillation. Groups of animals were given dosages of $2,3,4,5,6,7$ and 8 drops of insulin respectively, each drop containing approximately 5 units. The subsequent blood sugar determinations were made at intervals as nearly as possible each hour after the instillations until the fasting level had been essentially regained.

TABLE 1

Variations in blood sugar of untreated animals

\begin{tabular}{c|c|c|c|c}
\hline \hline Number & $\begin{array}{c}\text { Body } \\
\text { weight }\end{array}$ & $\begin{array}{c}\text { Time } \\
\text { of fast }\end{array}$ & Initial & Blood sugar (mgm: per 100 cc.) \\
\hline & & & & Time after initial (number of minutes in parentheses) \\
\hline 3 & 2.40 & 14 & 115 & $126(60) ; 102(120) ; 101(180) ; 103(240)$ \\
14 & 3.91 & 0 & 122 & $117(60) ; 120(120) ; 111(180) ; 124(240)$ \\
15 & 2.85 & 0 & 134 & $124(60) ; 129(120) ; 118(180) ; 126(240)$ \\
16 & 2.95 & 0 & 114 & $120(60) ; 116(120) ; 114(180) ; 107(240)$ \\
17 & 3.30 & 0 & 110 & $92(60) ; 114(120) ; 109(180) ; 115(240)$ \\
22 & 3.90 & 24 & 109 & $106(60) ; 108(150) ; 112(300) ; 110(420) ; 111(450)$ \\
23 & 3.35 & 24 & 97 & $103(60) ; 100(120) ; 100(240) ; 104(360) ; 105(400)$ \\
24 & 2.24 & 24 & 114 & $107(60) ; 116(120) ; 110(240) ; 110(360) ; 113(420)$ \\
\hline
\end{tabular}

\section{DISCUSSION}

From Chart 1 it will be seen that the results of conjunctival administration of insulin causes a fairly uniform and consistent drop in the sugar level in rabbits' blood over a period of about 4 to 5 hours. It must be borne in mind that there was a variable loss of insulin by failure to get the full dose in the rabbit's eye at every administration. Occasionally an animal did not get the expected drop in blood sugar level, which may have been due to the loss of too much of the insulin, or that a given rabbit would not respond for other reasons. It has been noted repeatedly by other investigators with subcutaneous administration of insulin that occasionally certain animals would not show the expected drop. Various explanations have been offered for this fact, and it is possible that some of these latter factors have played a part in the ineffectiveness of insulin in the eye at times. 
C. D. CHRISTIE AND R. F. HANZAL

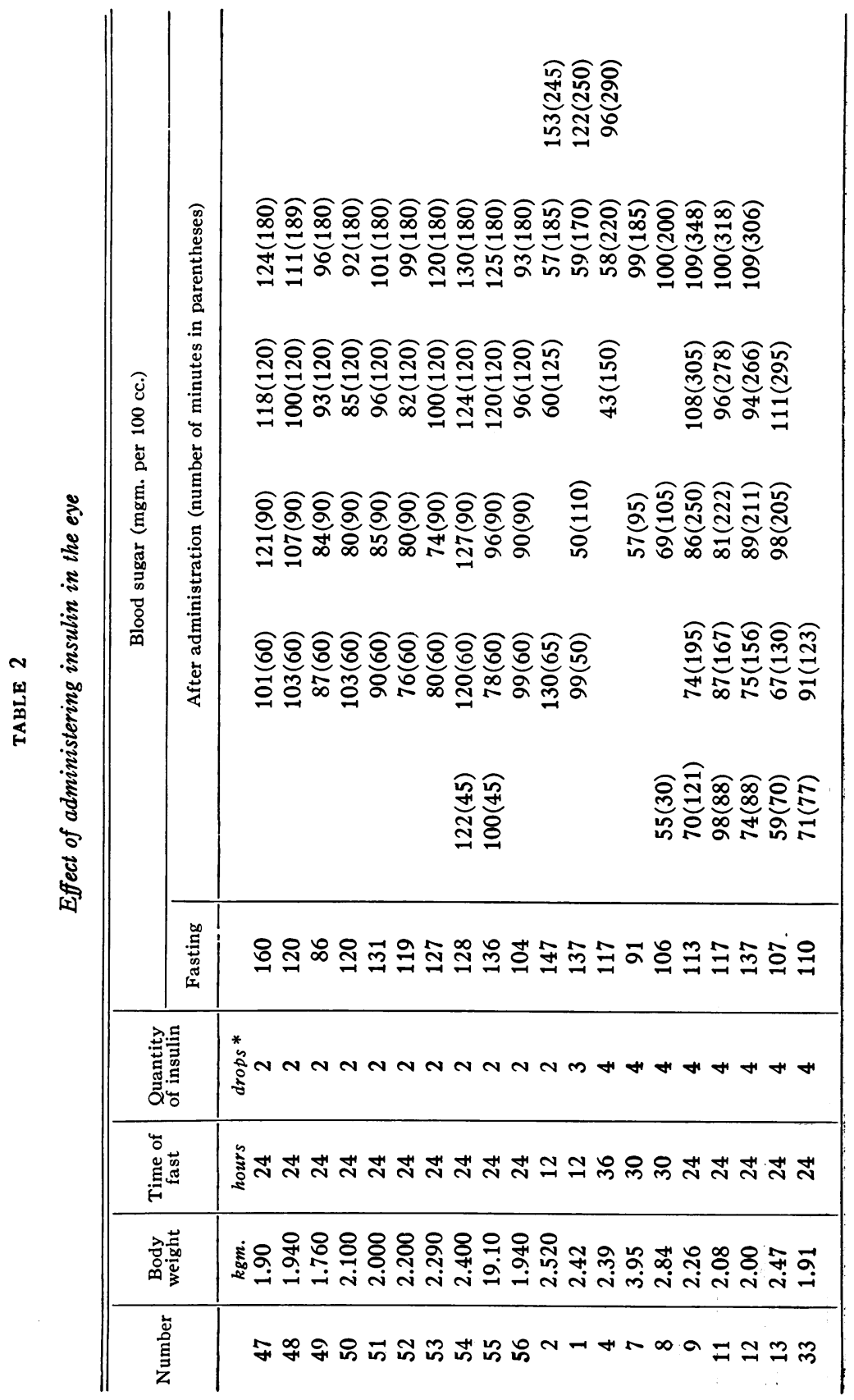




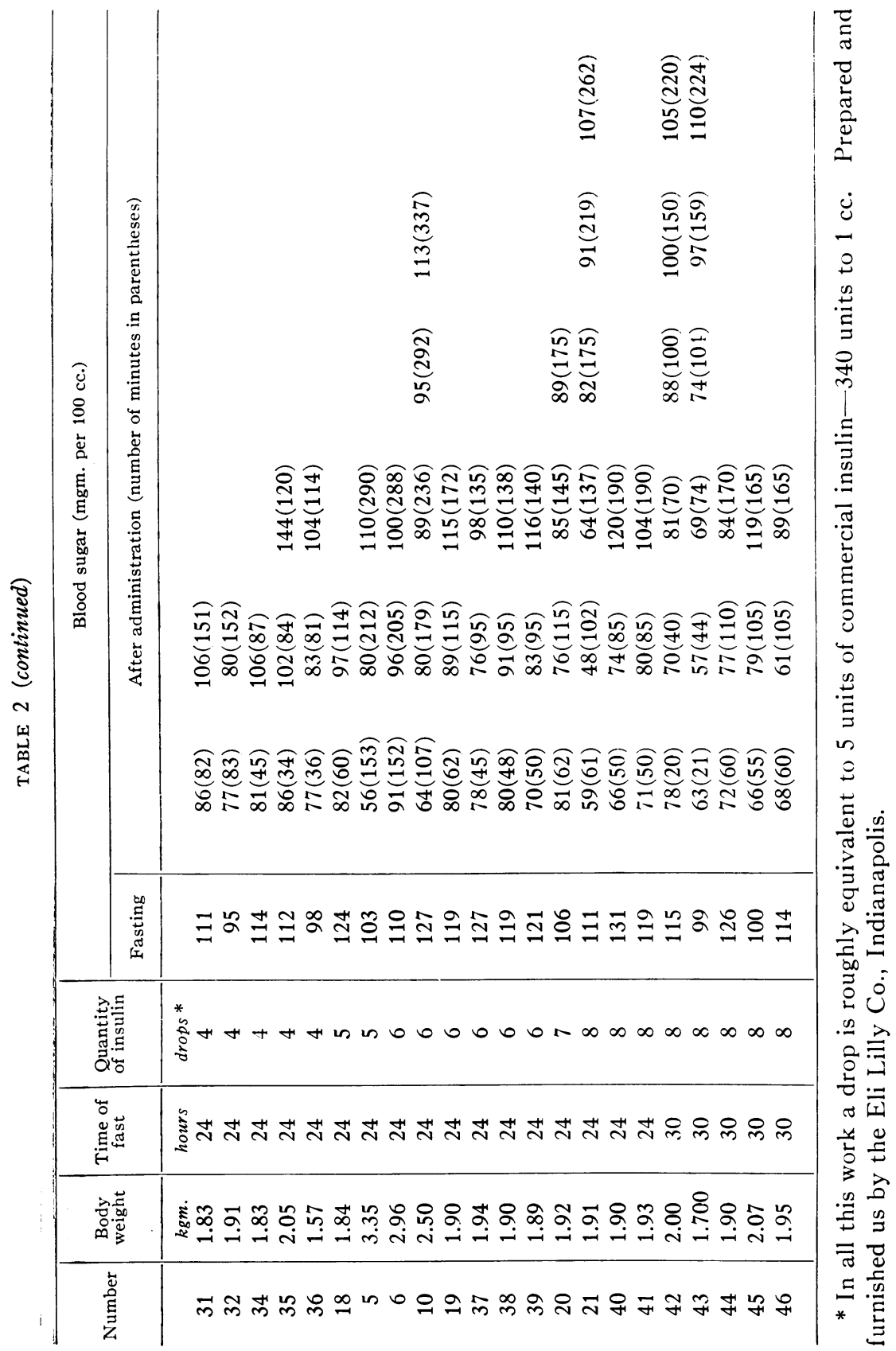


C. D. CHRISTIE AND R. F. HANZAL

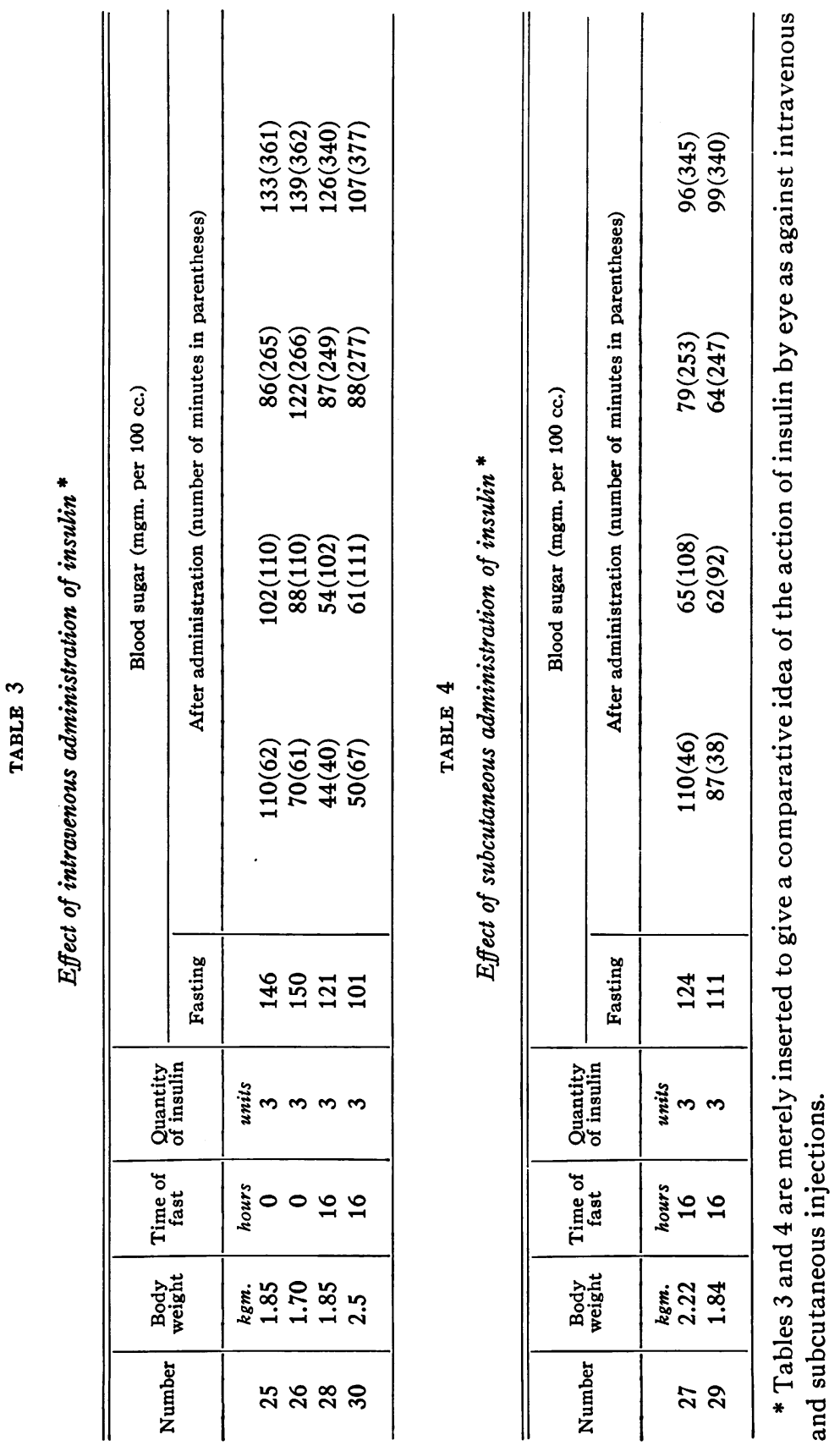


There can be no doubt, however, that the response was not always uniform. A few animals showed as much drop on a relatively small dose as others showed on a larger one. Occasionally a few of our animals showed symptoms of insulin shock.

The preparation of insulin which we used in these experiments was supplied to us by the Eli Lilly Co., Indianapolis. It contained 340

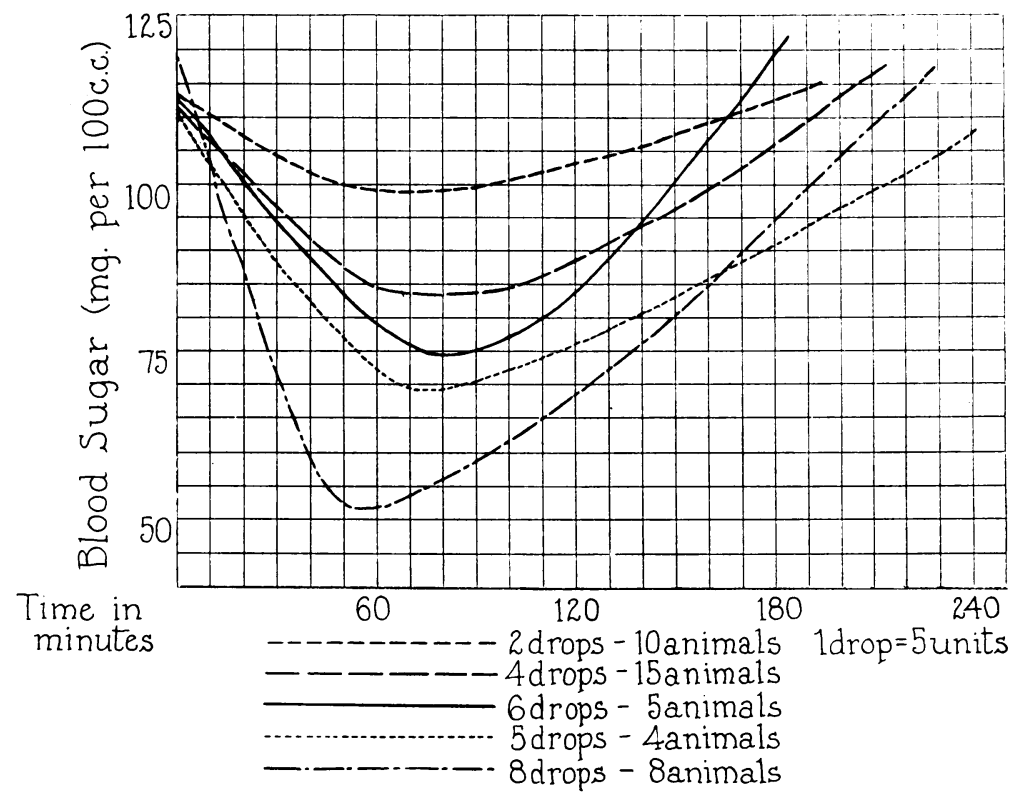

Chart 1. Effect of Conjunctival Administration of Ixsulin on Blood Sugar of Rabits

units to the cc. It had a $\mathrm{pH}$ of about 2.5 , and contained .2 per cent of phenol. We noted at times a white scum form over the rabbit's eye immediately after the insulin was instilled. This we believe was due to the buffer substances in the lachrymal secretion neutralizing the instilled insulin. Insulin is insoluble in a neutral medium.

We have not sufficient data to venture a guess as to the effectiveness of insulin by eye in the rabbit as compared to subcutaneous injections. It is our impression, however, that it requires about 60 per cent more.

We have seen no evidence to indicate that even commercial insulin is irritating to the eyes of rabbits. 


\section{CONCLUSIONS}

Insulin instilled into the conjunctiva is absorbed with great rapidity and gives rise to a fairly constant and consistent fall of blood sugar levels in rabbits.

The drop in blood sugar level persists for from 4 to 5 hours as against from 5 to 6 hours by the subcutaneous route.

Apparently it requires about 60 per cent more insulin by this method of administration than the subcutaneous route, although our experiments are not conclusive on this point.

We have seen nothing to make us believe that commercial insulin is irritating to the eyes of animals.

\section{BIBLIOGRAPHY}

1. Stammers, A. D., Physiol. Rev., 1926, vi, 630. A Review of Recent Advances in the Study of Blood Sugar and Diabetes. 